\begin{tabular}{lc}
\hline SCIENCE \& TECHNOLOGY \\
Journal homepage: htp://www.pertanika.upm.edu.my/ \\
\hline PERTANIKA
\end{tabular}

\title{
Optimisation of Culture Conditions for PLA-food-packaging Degradation by Bacillus sp. SNRUSA4
}

\author{
Suwapha Sawiphak* and Aroon Wongjiratthiti \\ Program of Biology, Faculty of Science and Technology, Sakon Nakhon Rajabhat University, \\ Sakon Nakhon, 47000, Thailand
}

\begin{abstract}
Polylactic acid (PLA) is increasingly used in food-packaging production. The screening of PLA-food-packaging-degrading bacteria and optimisation of culture conditions for the PLA-food-packaging degradation by PLA-food-packaging-degrading bacteria were investigated for bioplastic waste management purposes. Only bacterial strain SNRUSA4 exhibited an increase in optical density (OD) in Basal Medium (BM) supplemented with 1.0 $\mathrm{g} / \mathrm{L}$ of PLA-food-packaging as sole carbon source after 4 weeks of incubation. A weight loss of $7.3 \%$ and the rough and porous surface of PLA-food-packaging indicated that SNRUSA4 was a PLA-food-packaging-degrading bacterium. SNRUSA4 was able to degrade pure PLA which was confirmed from the clear zone formation around its colony on emulsified pure PLA agar plate. The 16S rRNA gene sequence of SNRUSA4 showed the similarity with thirteen Bacillus species. Hence, the strain SNRUSA4 was assigned as Bacillus sp. SNRUSA4. Response surface methodology with Box-Behnken Design was used to optimise the culture conditions including yeast extract concentration, initial $\mathrm{pH}$ value, temperature and agitation speed for growth and PLA-food-packaging degradation of Bacillus sp. SNRUSA4. The optimal conditions of Bacillus sp. SNRUSA4 was discovered in $\mathrm{BM}$ at initial $\mathrm{pH}$ value 7.02 with yeast extract concentration of $2.56 \%$ and

ARTICLE INFO

Article history:

Received: 11 September 2020

Accepted: 07 December 2020

Published: 22 January 2021

DOI: https://doi.org/10.47836/pjst.29.1.23

E-mail addresses:

ssuvapa@hotmail.com (Suwapha Sawiphak)

mic_610@hotmail.com (Aroon Wongjiratthiti)

* Corresponding author agitated at $205.28 \mathrm{rpm}$ at $31.68^{\circ} \mathrm{C}$. Under optimal conditions, the OD of Bacillus sp. SNRUSA4 was up to 1.955 , and the different OD between before and after optimisation was up to 1.752 . Furthermore, the PLAfood-packaging weight loss also increased from $7.30 \%$ to $87.10 \%$ indicating that the
\end{abstract}


PLA-food-packaging degradation under optimal conditions was higher than the unoptimised conditions. Therefore, Bacillus sp. SNRUSA4 is an efficient strain for degradation of PLA and PLA-food-packaging.

Keywords: Bacillus sp. SNRUSA4, biodegradation, Box-Behnken design, response surface methodology

\section{INTRODUCTION}

Plastics made from petroleum such as polyamides (nylon), polyethylene, polystyrene, and poly(vinyl chloride). are non-degradable materials which lead to the accumulation of plastic wastes in environment. Polylactic acid (PLA) is considered as an alternative plastic to reduce the environmental problem. Lactic acid (monomer of PLA) was produced through the fermentation of renewable resources and biodegradable materials (Tawakkal, et al., 2014; Muller et al., 2017). PLA is a nontoxic compound and is accepted as generally recognized as safe by FDA (Food and Drug Administration) (Tawakkal et al., 2014). PLAfood-packaging is widely used in drinking cups (Farah et al., 2016) and various food grade containers (Zhong et al., 2020). The production of PLA had increased from 140,000 tonnes per annum in 2011 to 800,000 tonnes per annum in 2020 (Mirabal et al, 2013). The PLAfood-packaging degradation depends on the environmental conditions. The degradation of PLA in natural condition (soil and sludge) spends more than 90 days (Boonmee et al., 2016). The usage rate of PLA-food-packaging is greater than the PLA degradation rate, potentially causing additional environmental problems in the future.

The PLA degradation occurs by cleavage of ester bonds between two lactic acid molecules. Hydrolytic (Elsawy et al., 2017), photolytic (Janorkar et al., 2007) and microbial degradation (Apinya et al., 2015; Liang et al., 2016; Lipsa et al., 2016; Bubpachat et al., 2018) are three recognised mechanisms of PLA degradation. Microbial degradation is one of the interesting topics of PLA degradation research, as the complete degradability of PLA does not cause any pollution to the environment (Qi et al., 2017). Karamanlioglu et al. (2014) demonstrated that PLA-food-packaging did not degrade in sterile soil and suggested that microorganisms as biocatalyst could help to degrade PLA-food-packaging. Microbial degradation of PLA-food-packaging by the two fungi, Aspergillus ustus and Penicillium verrucosum was first found by Szumigaj et al. (2008). Streptomyces sp. KKU215 is the first actinomycete strain for PLA-food-packaging degradation (Yottakot \& Leelavatcharamas, 2019). There have been no reports on PLA-food-packaging degradation by unicellular bacteria. Thus, isolation and screening of microorganisms capable of degrading PLA-foodpackaging is an interesting research.

The utilisation of Response Surface Methodology (RSM) based on Box-Behnken Design (BBD) for the optimisation of culture conditions is the currently accepted method (Khatoon \& Rai, 2020). This statistical technique can provide the information of interaction between parameters (Qi et al., 2015). Moreover, the degradation of PLA and PLA-food- 
packaging has been significantly increased through the use of RSM with BBD (Chaisu et al., 2012; Yottakot \& Leelavatcharamas, 2019).

Therefore, the aim of this research was to screen, identify and optimise culture conditions of PLA-food-packaging-degrading bacteria. RSM with BBD was used to determine the optimal culture conditions (concentration of yeast extract $(Y E)$, initial $\mathrm{pH}$ value $\left(p H_{i n i}\right)$, temperature $(T)$ and agitation speed $\left.(A S)\right)$ of Bacillus sp. SNRUSA4 growth for PLA-packaging degradation.

\section{MATERIALS AND METHODS}

\section{Screening of PLA-food Packaging-Degrading Bacteria}

PLA-food-packaging was purchased from Dairy Home Co., Ltd, Thailand. PLA-foodpackaging was cut into samples of size $1 \mathrm{~cm} \times 1 \mathrm{~cm}$, then PLA-food-packaging coupons was washed with $70 \%(\mathrm{v} / \mathrm{v})$ ethanol and allowed to air-dry until completely dry. The samples were collected from soils and composts to isolate the PLA-packaging-degrading bacteria. These samples were kept at $4^{\circ} \mathrm{C}$ until required.

The sterile Basal Medium (BM) ( $\mathrm{pH} 7.0$ ) was prepared by adding $4 \mathrm{~g}$ of $\left(\mathrm{NH}_{4}\right)_{2} \mathrm{SO}_{4}, 2$ $\mathrm{g}$ of $\mathrm{K}_{2} \mathrm{HPO}_{4}, 2 \mathrm{~g}$ of $\mathrm{KH}_{2} \mathrm{PO}_{4}$ and $0.5 \mathrm{~g}$ of $\mathrm{MgSO}_{4} \cdot 7 \mathrm{H}_{2} \mathrm{O}$ to $1 \mathrm{~L}$ of distilled water, and then autoclaved at $121^{\circ} \mathrm{C}$ for 15 minutes. The sterile BM was added $1 \mathrm{~g}$ of PLA-food-packaging coupons as sole carbon source.

In order to isolate PLA-food packaging degrading bacteria, $10 \mathrm{~g}$ of the samples was inoculated into $250 \mathrm{~mL}$ Erlenmeyer flask with $100 \mathrm{~mL}$ of sterilised BM containing $1 \mathrm{~g}$ of PLA-food-packaging coupons. The inoculated flask was incubated at $37^{\circ} \mathrm{C}$ and $180 \mathrm{rpm}$ in an incubator shaker for 7 days. After incubation, $10 \mathrm{~mL}$ of the culture was inoculated into sterilised BM containing $1 \mathrm{~g}$ of PLA-food-packaging coupon as sole carbon source. This experiment was performed five times with the same method. Then, each of the PLAfood-packaging coupons was transferred onto BM agar plates. The plates were incubated at $37^{\circ} \mathrm{C}$ for 7 days (Yottakot \& Leelavatcharamas, 2019). The colonies around PLA-foodpackaging coupons were purified by streak plate technique on Nutrient Agar (NA) plate. The purified isolates were stored on NA slant at $4^{\circ} \mathrm{C}$ and in $30 \%$ glycerol at $-10^{\circ} \mathrm{C}$.

PLA-food packaging-degrading bacteria was screened by analysing the growth in the sterile BM containing $1 \mathrm{~g}$ of PLA-food-packaging coupons as sole carbon source using the optical density (OD) at wavelength $600 \mathrm{~nm}$ (Lee et al., 2013). The cell suspension of selected stains was transferred to Nutrient Broth (NB) medium and shaken at $180 \mathrm{rpm}$ at $37^{\circ} \mathrm{C}$ for 24 hours, and then centrifuged for $10 \mathrm{~min}$ at $5,635 \mathrm{x} \mathrm{g}$. The precipitated cells were washed twice with $0.85 \%(\mathrm{w} / \mathrm{v}) \mathrm{NaCl}$. The cell density was adjusted to $\mathrm{OD}_{600}=1.0$ with $0.85 \%(\mathrm{w} / \mathrm{v}) \mathrm{NaCl}$. The optical density was measured by spectrophotometer. Cell suspension $(10 \mathrm{~mL})$ of each isolate was inoculated into $100 \mathrm{~mL}$ of the sterile BM containing $1 \mathrm{~g}$ of PLA-food-packaging coupons as sole carbon source, and then incubated at $37^{\circ} \mathrm{C}$ and 180 
rpm in an incubator shaker. The cell density was measured every week for 4 weeks. The sterilised BM, BM containing $1 \mathrm{~g}$ of PLA-food packaging coupons and BM with the cell were used as controls. The experiment was done in triplicate.

SNRUSA4, PLA-food-packaging-degrading bacterial strain was screened because of the increasing OD. The ability of SNRUSA4 to degrade PLA-food-packaging coupons was measured after 4 weeks of incubation by analysing weight loss and surface changes of the individual samples in the sterilised BM containing $1 \mathrm{~g}$ of PLA-food-packaging coupons as sole carbon source. The original PLA-food-packaging coupons and PLA-food-packaging coupons in BM without inoculation of SNRUSA4 after 4 weeks of incubation were used as controls.

Degradation of PLA-food-packaging coupons was assessed by measuring weight loss. The PLA-food-packaging coupons was washed with distilled water, and dried until constant weight in an electronic desiccator. The weight loss percentage of PLA-food-packaging coupons was calculated according to Equation 1 (Vey et al., 2007).

$$
\% \text { Weight loss }=\frac{m_{\text {ini }}-m_{\text {dry }}}{m_{\text {ini }}} \times 100 \%
$$

where $\mathrm{m}_{\text {ini }}$ is the initial weight of original PLA-food-packaging coupon; $\mathrm{m}_{\mathrm{dry}}$ is the dry weight of PLA-food-packaging coupon after degrading.

The change in surface morphology of the PLA-food-packaging coupon was checked after 4 weeks of incubation by Scanning Electron Microscope (SEM) (SEC, model SNE-4500M). The PLA-food-packaging coupons were coated with gold before SEM examination.

The pure PLA degradability of PLA-food-packaging-degrading bacterial strain SNRUSA4 was confirmed by the clear zone around bacterial strain SNRUSA4 colony on emulsified PLA agar plate after 2 weeks of incubation at $37^{\circ} \mathrm{C}$. PLA pellet (2003D grade, melting temperature $210^{\circ} \mathrm{C}$, average molecular weight $200,000 \mathrm{~g} / \mathrm{mol}$ ) was obtained from NatureWorks LLC (U.S.A.). Emulsified PLA agar was prepared as follows by the method of Yottakot \& Leelavatcharamas (2019).

\section{Identification of Selected Strain}

The PLA-food-packaging-degrading bacterial isolate SNRUSA4 was identified on the basis of 16S rRNA gene sequence analysis. DNA of SNRUSA4 was extracted using DNA mini kit (Geneaid Biotech Ltd., Taiwan). The 16S rRNA gene was amplified from the genomic DNA by PCR using the two primers, 20F and 1500R (Brosius et al., 1981). PCR was performed using a Taqpolymerase (Cinnagen, Iran). The PCR program using following cycling step, initial denaturation at $96^{\circ} \mathrm{C}$ for $3 \mathrm{~min}$, and then 25 cycles with denaturation at $94^{\circ} \mathrm{C}$ for 1 $\min , 50^{\circ} \mathrm{C}$ for $1 \mathrm{~min}, 72^{\circ} \mathrm{C}$ for $2 \mathrm{~min}$. A final extension was performed at $72^{\circ} \mathrm{C}$ for $3 \mathrm{~min}$. 
The PCR product was purified through $1.0 \%$ agarose gel using the GenepHlowTM Gel/ PCR Kit (Geneaid). DNA sequencing of the purified PCR products was carried out on an ABI Prism ${ }^{\circledR}$ 3730XL DNA Sequence (Applied Biosystems, Foster City, California, USA). The sequences were aligned using program CLUSTAL X (version 1.8) (Thompson, 1997) in BioEdit program (Hall, 1999). Phylogenetic trees were reconstructed by the neighborjoining method (Saitou \& Nei, 1987) and maximum-likelihood (Felsenstein, 1985) treemaking algorithms by using the MEGA version 6.0 (Tamura et al., 2013).

\section{Optimisation of Bacillus sp. SNRUSA4 Growth Conditions for PLA-food- packaging Degradation using Statistical Design}

The optimisation of Bacillus sp. SNRUSA4 growth conditions for enhancement of degradation of PLA-food-packaging was investigated. RSM based on BBD was used to design and optimise the culture condition of Bacillus sp. SNRUSA4 by Design-Expert ${ }^{\circledR}$ Software Version 10 (Trial Version). $Y E$ concentration, $p H_{i n i}, T$ and $A S$ were optimised in this research. The suitable ranges of each factor for RSM were selected based on the preliminary single factor experiments. The ranges of four independent variables including $Y E$ concentration $(0.2-3.0 \%), p H_{\text {ini }}(4.0-10.0), T\left(27-47^{\circ} \mathrm{C}\right)$ and $A S(150-250 \mathrm{rpm})$ are shown in Table 1. The OD of Bacillus sp. SNRUSA4 was examined after 2 days of incubation.

Table 1

Coded and levels of factors in BBD

\begin{tabular}{lcccc}
\hline \multirow{2}{*}{ Independent variables } & Code & \multicolumn{3}{c}{ Levels } \\
\cline { 3 - 5 } & & -1 & 0 & 1 \\
\hline$Y E$ concentration $(\%)$ & $X_{1}$ & 0.2 & 1.6 & 3.0 \\
\hline$p H_{\text {ini }}$ & $X_{2}$ & 4.0 & 7.0 & 10.0 \\
\hline$T(\mathrm{C})$ & $X_{3}$ & 27 & 37 & 47 \\
\hline$A S(\mathrm{rpm})$ & $X_{4}$ & 150 & 200 & 250 \\
\hline
\end{tabular}

The results of optimisation were confirmed by OD after 2 days of cultivation and degradation of PLA-food-packaging after 4 weeks of cultivation under the optimal conditions based on the results of RSM.

\section{RESULTS AND DISCUSSION}

\section{Screening of PLA-food-packaging-degrading Bacteria}

Only one bacterial strain, SNRUSA4 revealed increasing OD at 0.203 in BM with PLAfood-packaging as sole carbon source after 4 weeks of cultivation (Figure 1). In contrast, the OD of all controls (the sterile BM, the sterile BM containing $1 \mathrm{~g}$ of PLA-food-packaging coupons and the sterile BM with SNRUSA4) did not increase after 4 weeks of cultivation (Figure 1). SNRUSA4 could grow in the BM medium with PLA-food-packaging coupons 
which indicated that it was able to degrade the PLA-food-packaging material as a carbon source. The increase of cell density in BM medium supplemented with a bioplastic as a carbon source could indicate the capability of microbe to degrade bioplastic (Jeon \& Kim, 2013; Lee et al., 2013; Yottakot \& Leelavatcharamas, 2019).

The bacterial strain SNRUSA4 was isolated from compost. This result is also consistent with the study of Kim \& Park (2010) and Jeon \& Kim (2013). Kim \& Park (2010) could isolate PLA-degrading bacteria, Bordetella petrii PLA-3 from compost. Jeon \& Kim (2013) found Stenotrophomonas maltophilia LB 2-3 from compost which could degrade PLA. Therefore, compost is a suitable bacterial source sample to isolate and screening the PLA-degrading bacteria.

The PLA-food-packaging coupons had a weight loss of $7.30 \pm 0.11 \%$ after degradation by SNRUSA4 for 4 weeks. The weight loss of PLA-food-packaging coupons did not decrease in the absence of bacterial cells. The weight loss can be applied to measure degradation of the plastics (Muhonja et al., 2018). Although, the SNRUSA4 strain can degrade the PLA-food-packaging coupon, the PLA-food-packaging degradation of this strain seems to be very low. The increasing nutrients such as $Y E$ and gelatin in BM medium can lead to an increase in PLA degradability of microorganism (Jarerat \& Tokiwa, 2003; Jarerat et al., 2003; Konkit et al., 2012; Zhou et al., 2017; Bubpachat et al., 2018; Yottakot \& Leelavatcharamas, 2019; Decorosi et al., 2019). Thus, the optimisation of culture conditions is essential for the degradation of PLA-food-packaging.

The scanning electron micrographs of the PLA-food-packaging coupons before and after 4 weeks of degradation are shown in Figure 2. There was no significant difference between the surface of PLA-food-packaging coupons before degradation (Figure 2a) and

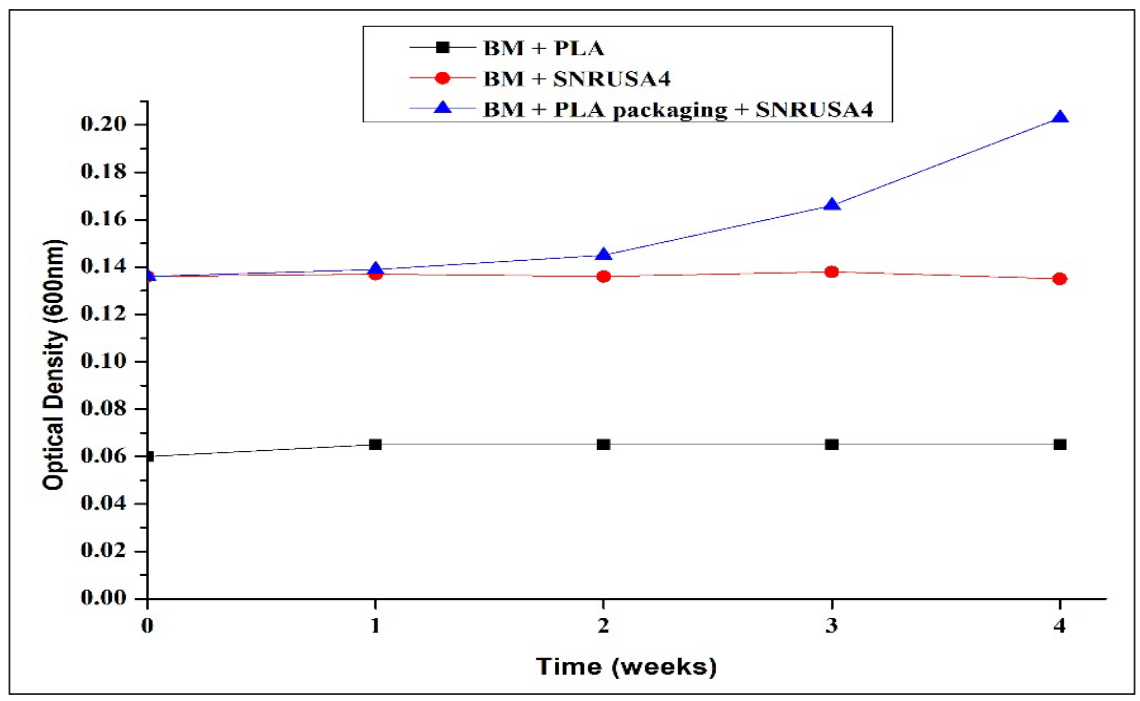

Figure 1. The increase in cell density of strain SNRUSA4 after incubated in the sterile BM medium containing PLA-food-packaging for 4 weeks 
the surface of PLA-food-packaging coupons after degradation in BM medium without inoculation of SNRUSA4 (Figure 2b). Figure 2c showed the roughness and porosity on the surface of the PLA-food-packaging coupons after degradation in BM medium with inoculation of SNRUSA4. This finding is similar to the result of Kim et al. (2017) evaluating the morphological changes in the surface of PLA film after the degradation by using SEM.

The standard clear zone method was commonly used to analyse the PLA degradation by microorganism (Liang et al., 2016; Bubpachat et al., 2018; Butbunchu \& Pathom-Aree, 2019). The clear zone formation around the colony was formed by microbe able to degrade suspended PLA in emulsified PLA agar medium. This method is therefore applicable for the confirmation of PLA degradation by PLA-food-packaging-degrading bacterial strain SNRUSA4. SNRUSA4 could degrade PLA in emulsified PLA agar plate due to the clear zone formation around the colony within 2 weeks of incubation at $37^{\circ} \mathrm{C}$ (Figure 3 ). The microorganisms can produce enzymes to degrade the biopolymers (Penkhrue et al., 2015;

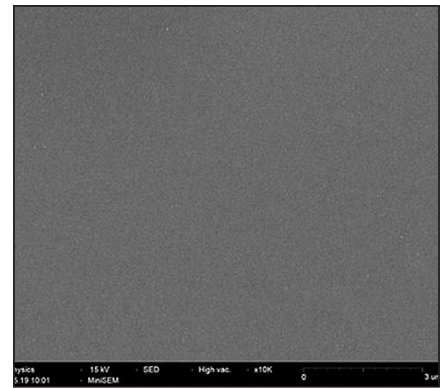

(a)

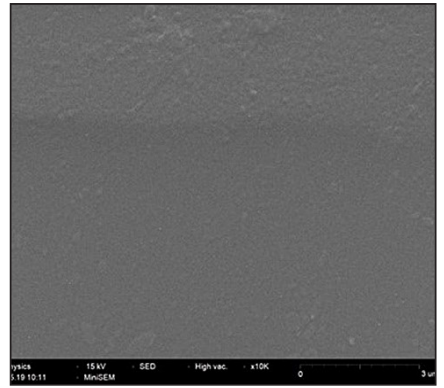

(b)

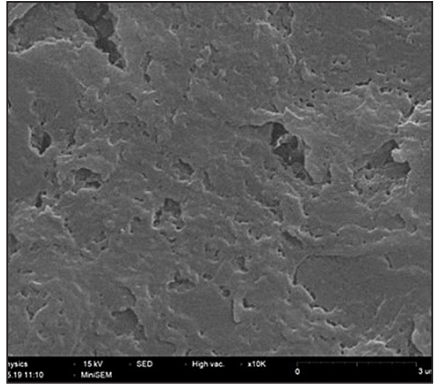

(d)

Figure 2. SEM micrographs of the surface of PLA-food-packaging coupons: (a) the surface before degradation; (b) the surface after incubation in BM medium without the strain; and (c) after the SNRUSA4 strain degradation

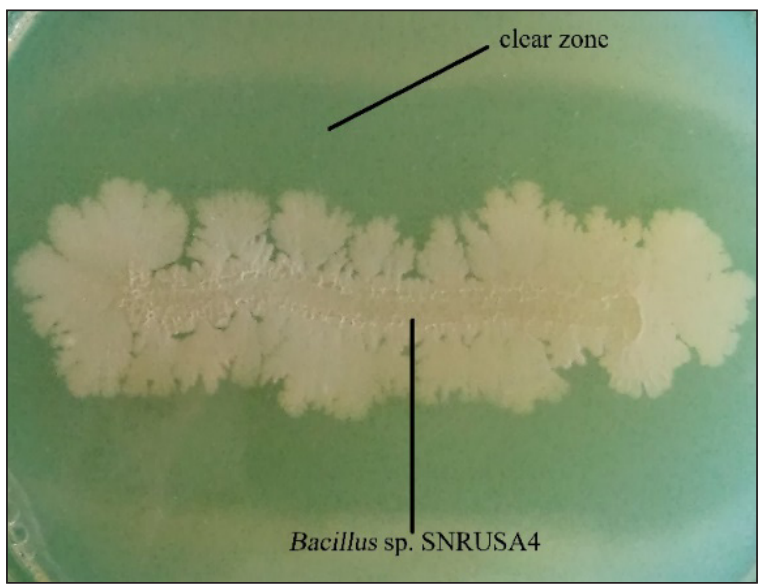

Figure 3. Clear zone formation by Bacillus sp. SNRUSA4 on emulsified PLA agar after 2 weeks of incubation at $37^{\circ} \mathrm{C}$ 
Phukon et al., 2012). The formation of clear zone around SNRUSA4 colonies indicates that SNRUSA4 can use PLA as sole carbon source for growth.

\section{Identification of SNRUSA4 Strain}

The 16S rDNA sequence of the SNRUSA4 strain is related to more than $99 \%$ with the genus Bacillus. This isolate is named as Bacillus sp. SNRUSA4 (Figure 4). The 16S rDNA sequence of Bacillus sp. SNRUSA4 showed similarity with Bacillus methylotrophicus KACC 13105 (99.93\%), Bacillus siamensis KCTC 13613 (99.85\%), Bacillus amyloliquefaciens subsp. plantarum FZB42 (99.78\%), Bacillus subtilis subsp. subtilis NCIB 3610 (99.70\%), Bacillus amyloliquefaciens subsp. amyloliquefaciens DSM 7 (99.63\%), Bacillus subtilis subsp. inaquosorum KCTC 13429 (99.63\%), Bacillus tequilensis KCTC 13622 (99.63\%), Bacillus vallismortis DV1-F-3 (99.55\%), Bacillus atrophaeus JCM 9070 (99.48\%), Bacillus subtilis subsp. spizizenii NRRL B-23049 (99.48\%), Brevibacterium halotolerans DSM 8802 (99.48\%), Bacillus mojavensis RO-H-1 (99.41\%) and Bacillus vanillea XY18 (99.40\%). The 16S rDNA sequence of Bacillus sp. SNRUSA4 was submitted in the GenBank database

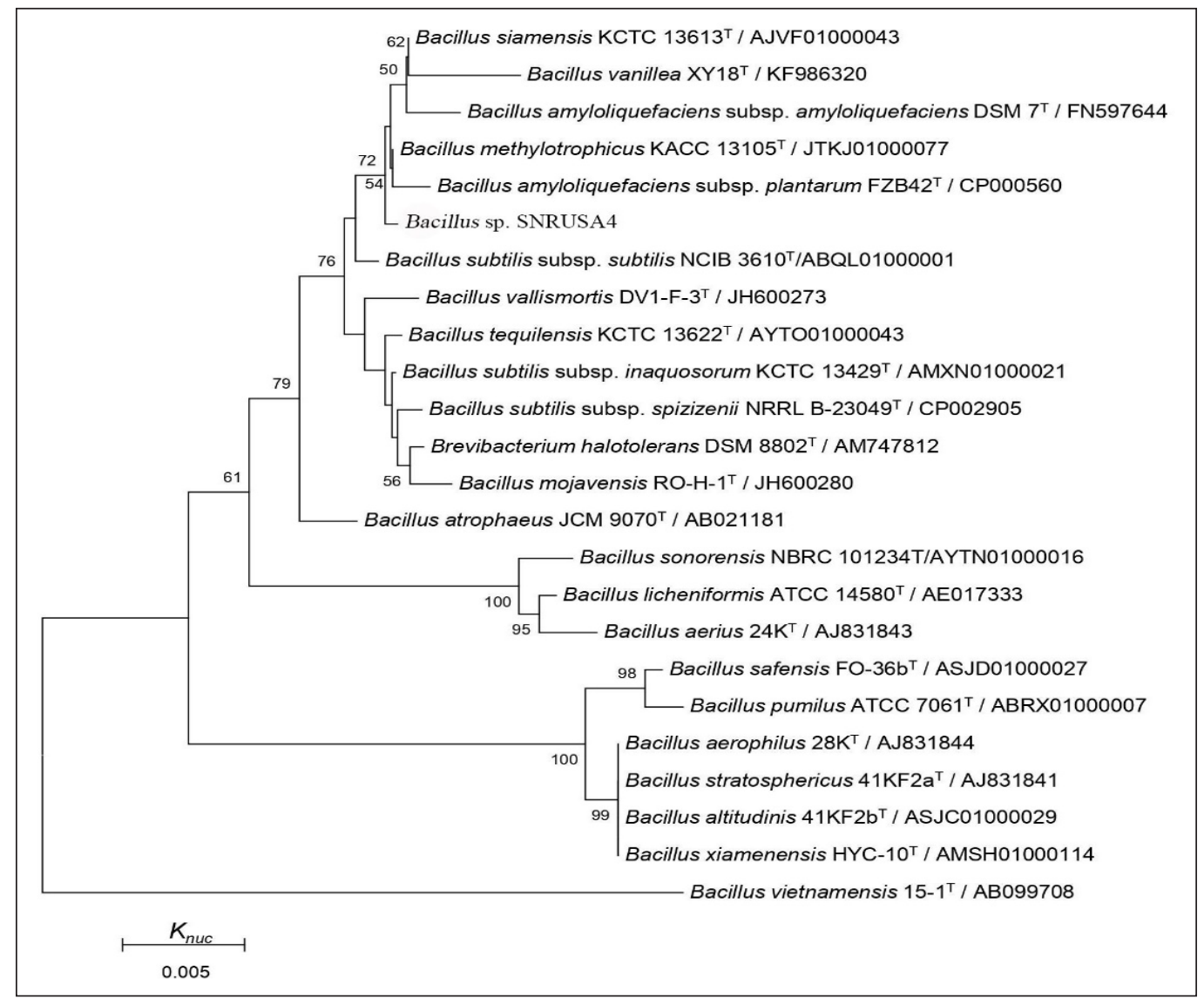

Figure 4. Phylogenetic tree of strain SNRUSA4 and related species of the genus Bacillus 
system with the accession number MT913031. All of thirteen Bacillus species have not been reported yet to being able to degrade PLA. Therefore, Bacillus sp. SNRUSA4 is a novel species for PLA and PLA-food-packaging degradation.

\section{Optimization of Growth Conditions by Bacillus sp. SNRUSA4}

The four factors including $Y E$ concentration $(\%)\left(X_{1}\right), p H_{\text {ini }}\left(X_{2}\right), T\left({ }^{\circ} \mathrm{C}\right)\left(X_{3}\right)$ and $A S(\mathrm{rpm})$ $\left(X_{4}\right)$ were optimised by RSM using BBD. Twenty-eight experiments with three levels of each factor and its responses are shown in Table 2.

Table 2

Experimental conditions of Box Behnken design for Bacillus sp. SNRUSA4 growth

\begin{tabular}{|c|c|c|c|c|c|c|}
\hline \multirow{2}{*}{$\begin{array}{l}\text { Run } \\
\text { No. }\end{array}$} & \multirow{2}{*}{$\begin{array}{c}Y E \text { concentration } \\
(\%)\end{array}$} & \multirow{2}{*}{$p H_{i n i}$} & \multirow{2}{*}{$T\left({ }^{\circ} \mathrm{C}\right)$} & \multirow{2}{*}{$A S(\mathrm{rpm})$} & \multicolumn{2}{|c|}{ Optical Density (600nm) } \\
\hline & & & & & Experiment & Predicted \\
\hline 1 & 3.0 & 7 & 37 & 250 & 1.912 & 1.687 \\
\hline 2 & 0.2 & 4 & 37 & 200 & 0.007 & -0.247 \\
\hline 3 & 1.6 & 10 & 27 & 200 & 0.034 & 0.125 \\
\hline 4 & 1.6 & 10 & 37 & 150 & 0.079 & 0.073 \\
\hline 5 & 1.6 & 7 & 37 & 200 & 1.849 & 1.787 \\
\hline 6 & 3.0 & 7 & 37 & 150 & 1.666 & 1.501 \\
\hline 7 & 0.2 & 7 & 47 & 200 & 0.711 & 1.029 \\
\hline 8 & 1.6 & 7 & 47 & 150 & 0.740 & 0.888 \\
\hline 9 & 1.6 & 4 & 47 & 200 & 0.009 & -0.268 \\
\hline 10 & 1.6 & 7 & 27 & 150 & 1.545 & 1.503 \\
\hline 11 & 0.3 & 10 & 37 & 200 & 0.029 & 0.242 \\
\hline 12 & 0.2 & 7 & 37 & 250 & 1.250 & 1.228 \\
\hline 13 & 1.6 & 10 & 47 & 200 & 0.011 & -0.255 \\
\hline 14 & 1.6 & 4 & 37 & 250 & 0.009 & 0.241 \\
\hline 15 & 1.6 & 7 & 47 & 250 & 1.324 & 1.325 \\
\hline 16 & 0.2 & 10 & 37 & 200 & 0.003 & -0.232 \\
\hline 17 & 1.6 & 7 & 27 & 250 & 1.638 & 1.449 \\
\hline 18 & 3.0 & 4 & 37 & 200 & 0.014 & 0.208 \\
\hline 19 & 1.6 & 7 & 37 & 200 & 1.743 & 1.787 \\
\hline 20 & 3.0 & 7 & 27 & 200 & 1.953 & 1.863 \\
\hline 21 & 0.2 & 7 & 27 & 200 & 0.621 & 0.772 \\
\hline 22 & 1.6 & 4 & 27 & 200 & 0.010 & 0.900 \\
\hline 23 & 0.2 & 7 & 37 & 150 & 0.991 & 1.030 \\
\hline 24 & 1.6 & 7 & 37 & 200 & 1.819 & 1.787 \\
\hline 25 & 3.0 & 7 & 47 & 200 & 0.794 & 0.868 \\
\hline 26 & 1.6 & 10 & 37 & 250 & 0.051 & 0.253 \\
\hline 27 & 1.6 & 7 & 37 & 200 & 1.738 & 1.787 \\
\hline 28 & 1.6 & 4 & 37 & 150 & 0.014 & 0.037 \\
\hline
\end{tabular}


The results of the experimentation obtained from BBD were fitted to a second order polynomial model to explain the dependence of Bacillus sp. SNRUSA4 growth on the four factors. The response surface regression model is shown as Equation 2:

$$
\begin{gathered}
Y=-13.47006+\left(1.47093 X_{1}\right)+\left(2.35354 X_{2}\right)+\left(0.23731 X_{3}\right)+ \\
\left(0.014561 X_{4}\right)+\left(0.00113095 X_{1} X_{2}\right)-\left(0.022357 X_{1} X_{3}\right)-\left(0.0000464286 X_{1} X_{4}\right)- \\
\left(0.000183333 X_{2} X_{3}\right)-\left(0.000038333 X_{2} X_{4}\right)+\left(0.0002455 X_{3} X_{4}\right)-\left(0.14887 X_{1}^{2}\right) \\
-\left(0.16692 X_{2}^{2}\right)-\left(0.00361917 X_{3}^{2}\right)-\left(0.00005 .34667 X_{4}^{2}\right)
\end{gathered}
$$

where $Y$ is the predicted $\mathrm{OD}$, and $X_{1}, X_{2}, X_{3}$ and $X_{4}$ are the independent variables of $Y E$ concentration, $p H_{\text {ini }}, T$ and $A S$, respectively.

The significance and adequacy of the quadratic response surface model was tested by analysis of variance (ANOVA). The results of the second order response surface model fitting in the form of ANOVA are given in Table 3. Even though, the lack of fit was significant (0.0120), the response surface regression model was highly significant with P-value $<0.0001$ and $\mathrm{F}$-value $=19.33$. In addition, the coefficient of determination $\mathrm{R}^{2}(0.9542)$ and the adjusted coefficient of determination $\mathrm{R}^{2}(0.9048)$ were also found acceptable $(>0.90)$ (Chen et al., 2009), which indicated the suitability of the response surface regression model for accurate prediction and analysis of Bacillus sp. SNRUSA4 growth.

The linear effect of $Y E$ concentration and $T$ showed significant impact on OD of Bacillus sp. SNRUSA4 with P-value of 0.0052 and 0.0194 , respectively. The quadratic effect of $Y E$ concentration $(\mathrm{p}$-value $=0.0106), p H_{\text {ini }}(\mathrm{p}$-value $<0.0001)$ and $T(\mathrm{p}$-value $=0.0027)$ presented great influence on the cell density, indicating that the effect of various factors on OD of Bacillus sp. SNRUSA4 was not a simple linear relationship but a significant surface relationship (Yun et al., 2018). There is an interaction between YE concentration and $T$ because the interaction effect between two factors was significant.

RSM was used to predict the optimal culture conditions of Bacillus sp. SNRUSA4. The three-dimensional (3D) response surface plots were generated from regression equation by considering two test variables at one time, while the other two variables were maintained at their middle level. The relationship between the variables and response was visualised through 3D response surface or contour plot to analyse the effects of each factors on the growth of Bacillus sp. SNRUSA4. The optimal level of each factor for maximal response, the impact of independent factors and the impact of interaction effect of each factor were determined with the aid of 3D response surface plots. The 3D response surface plots and contour plots are demonstrated in Figure 5(A-F). The shape of 3D response surface plots was convex, which indicated that the well-defined optimal variables were found. 
Table 3

Analysis of variance (ANOVA) for BBD results used for optimizing growth by Bacillus sp. SNRUSA4

\begin{tabular}{|c|c|c|c|c|c|}
\hline Source & SS & $\mathrm{df}$ & MS & $F$-value & $P$-value \\
\hline Model & 15.56 & 14 & 1.11 & 19.33 & $<0.0001$ \\
\hline$Y E$ concentration & 0.65 & 1 & 0.65 & 11.27 & 0.0052 \\
\hline$p H_{\text {ini }}$ & 0.001728 & 1 & 0.001728 & 0.030 & 0.8650 \\
\hline$T$ & 0.41 & 1 & 0.41 & 1.91 & 0.0194 \\
\hline$A S$ & 0.11 & 1 & 0.11 & 0.280 & 0.1899 \\
\hline$Y E$ concentration $* p H_{i n i}$ & 0.00009025 & 1 & 0.00009025 & 0.00157 & 0.9690 \\
\hline$Y E$ concentration* $T$ & 0.39 & 1 & 0.39 & 6.82 & 0.0216 \\
\hline$Y E$ concentration $* A S$ & 0.00004225 & 1 & 0.00004225 & 0.0007348 & 0.9788 \\
\hline$p H_{i n i}^{*} T$ & 0.000121 & 1 & 0.000121 & 0.002105 & 0.9641 \\
\hline$p H_{\text {ini }} * A S$ & 0.0001323 & 1 & 0.0001323 & 0.0023 & 0.9625 \\
\hline$T^{*} A S$ & 0.060 & 1 & 0.060 & 1.05 & 0.3246 \\
\hline $\begin{array}{l}Y E \text { concentration } * Y E \\
\text { concentration }\end{array}$ & 0.51 & 1 & 0.51 & 8.89 & 0.0106 \\
\hline$p H_{i n i} * p H_{i n i}$ & 13.54 & 1 & 13.54 & 235.52 & $<0.0001$ \\
\hline$T^{*} T$ & 0.79 & 1 & 0.79 & 13.67 & 0.0027 \\
\hline$A S * A S$ & 0.11 & 1 & 0.11 & 1.86 & 0.1953 \\
\hline Lack of Fit & 0.74 & 10 & 0.074 & 24.06 & 0.0120 \\
\hline Pure Error & 0.009205 & 3 & 0.003068 & & \\
\hline Cor Total & 16.30 & 27 & & & \\
\hline $\begin{array}{l}\mathrm{R}^{2}=0.9542 \\
\text { Adjusted } \mathrm{R}^{2}=0.9048 \\
\text { Predicted } \mathrm{R}^{2}=0.7382\end{array}$ & & & & & \\
\hline
\end{tabular}

$Y E$ is one of the important factors for the optimisation of the growth conditions. It is a complex organic nitrogen source not only contain nitrogen but also certain vitamin $\mathrm{B}$, sulphur, and trace nutrients, and widely used as an ingredient in the media for microorganism cultivation (Kalil et al., 2008). As shown in Figure 5(A), (B) and (C), when we increased the concentration of $Y E$ up to $2.56 \%$, a maximal growth of Bacillus sp. SNRUSA4 was observed. The results of this study indicate that $Y E$ is a necessary factor for Bacillus growth and are similar to other Bacillus spp. such as Bacillus licheniformis (Hassaan et al., 2014), Bacillus subtilis SF4-3 (Tian et al., 2016), Bacillus sp. (Biniarz et al., 2018) and Bacillus aryabhattai KIIT BE-1 (Ojha et al., 2020).

The $p H_{\text {ini }}$ of culture medium plays significant role in bacterial growth. It was clear from Fig. 5(B), (D) and (E) that the medium with $\mathrm{pH} 7.02$ was found to be the best $p H_{i n i}$ providing the highest Bacillus sp. SNRUSA4 growth. The optimal pH of most Bacillus was discovered at neutral pH such as Bacillus megaterium (Mohanrasu et al., 2020), Bacillus cereus sp. BNPI-92 (Mohammed et al., 2019) and Bacillus subtilis (Kim et al., 2020). 

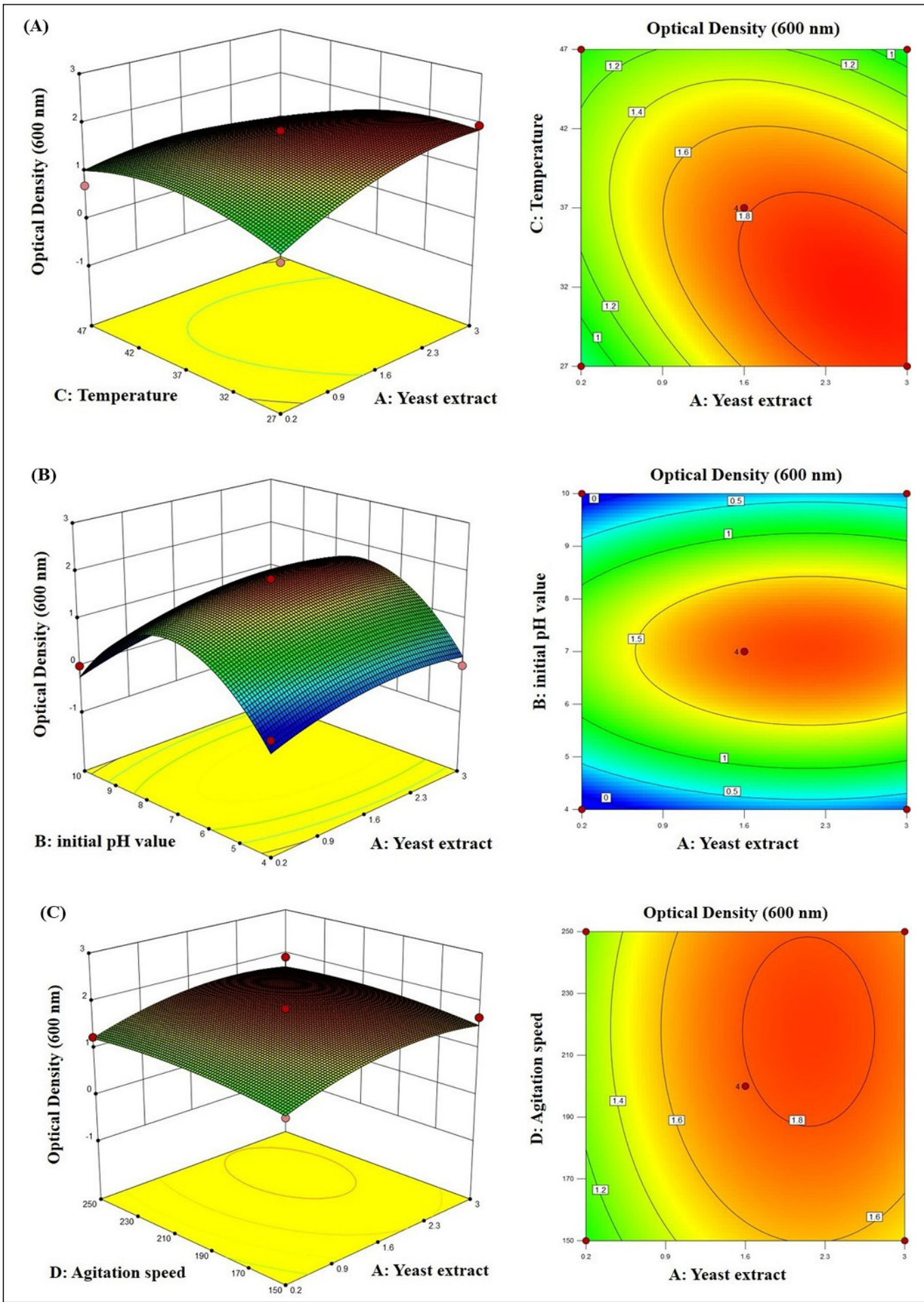

Figure 5. The 3D plots and contour plots showing the effect of (A) $Y E$ concentration and $T$, (B) $Y E$ concentration and $p H_{\text {ini }}$, and (C) $Y E$ concentration and $A S$ 

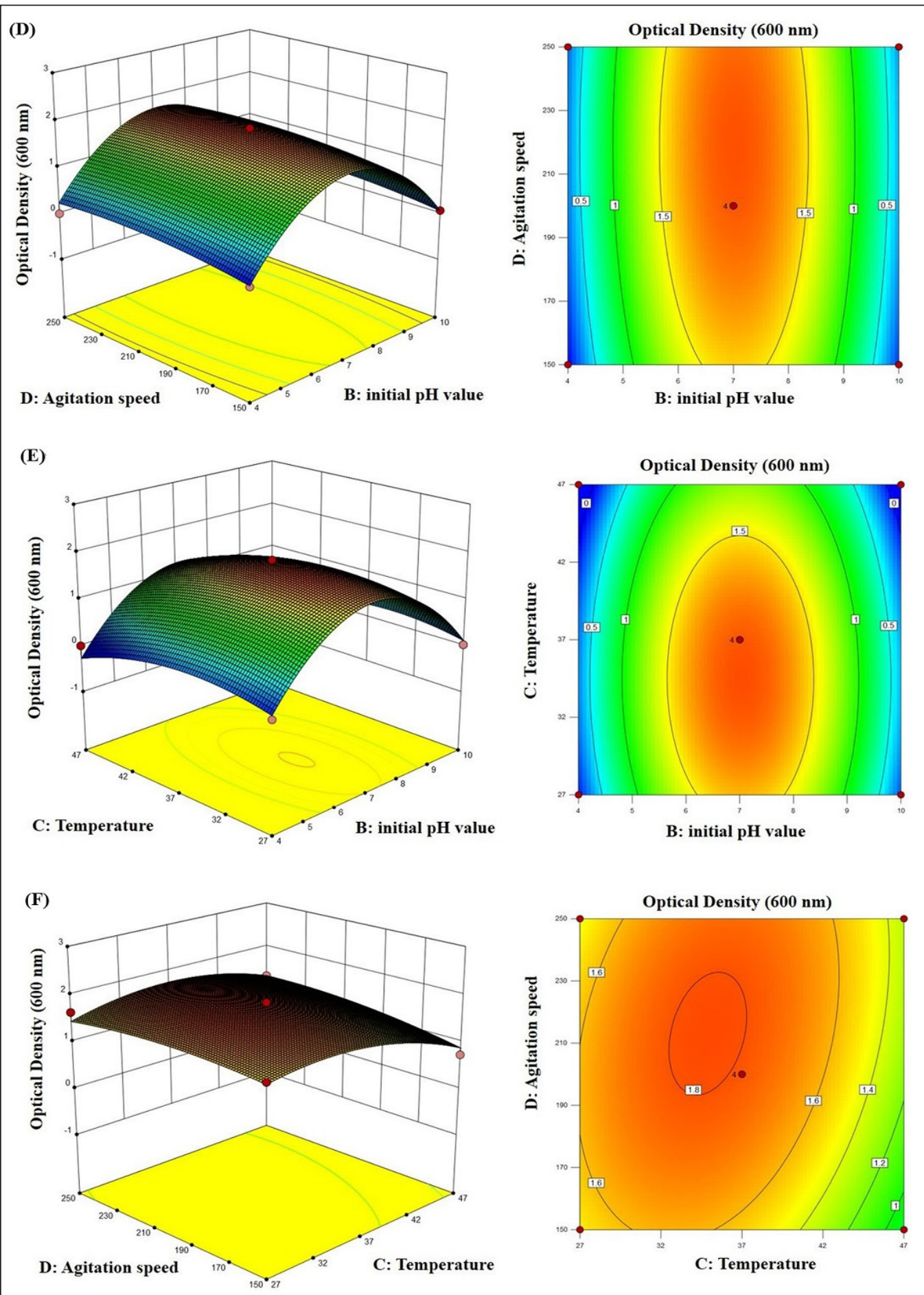

Figure 5. (continue) The 3D plots and contour plots showing the effect of (D) $p H_{\text {ini }}$ and $A S$, (E) $p H_{i n i}$ and $T$, (F) $T$ and $A S$. 
$T$ is an important environmental variable in microbial culture influencing enzyme activity, metabolite production and microbial growth (Logan \& Vos, 2015). The optimal $T$ of Bacillus sp. SNRUSA4 from the response surface analysis was $31.68^{\circ} \mathrm{C}$ [Figures 5(A), (E) and (F)]. Bacillus spp. are mesophilic bacteria that grow best at optimal $T$ range of 30-37 C. (Khatoon \& Rai, 2020; Naskar et al., 2020; Kim et al., 2020).

The $A S$ directly affects the oxygen transfer rate (OTR), a parameter that plays an important role in metabolism of aerobic Bacillus spp. (Bratcher, 2018). The $A S$ of 205.28 rpm was optimal $A S$ for Bacillus sp. SNRUSA4 cultivation [Figure 5(C), (D) and (F)]. This result conforms with a previous report by Unrean et al. (2012) who found that the highest cell density of Bacillus subtilis K-C3 was achieved at $A S$ of $200 \mathrm{rpm}$.

In conclusion, the predicted optimal conditions of $Y E$ concentration, $p H_{i n i}, T$ and $A S$ from the response surface curves and contour plots were $2.56 \%, 7.02,31.68^{\circ} \mathrm{C}$ and 205.28 rpm, respectively. At these conditions, predicted OD of Bacillus sp. SNRUSA4 was 1.921 (Table 4).

Table 4

The optimal values of test factors, and predicted maximum optical density

\begin{tabular}{lc}
\hline Variables & Value \\
\hline$Y E$ concentration $(\%)$ & 2.56 \\
$p H_{\text {ini }}$ & 7.02 \\
$T\left({ }^{\circ} \mathrm{C}\right)$ & 31.68 \\
$A S(\mathrm{rpm})$ & 205.28 \\
predicted maximum optical density & 1.921 \\
\hline
\end{tabular}

The verification experiment was carried out under the optimal conditions based on the results of RSM for the model validation. The OD after 2 days of cultivation and PLAfood-packaging degradation after 4 weeks of cultivation were investigated to confirm the accurate optimisation results. The predicted OD (1.921) was close to the OD of Bacillus sp. SNRUSA4 at optimal conditions (1.955). The result of this experiment proved that the model is reasonable. Moreover, regarding the PLA-food-packaging degradation, the weight loss of PLA-food-packaging under the optimal conditions by Bacillus sp. SNRUSA4 had greatly increased, up to $87.10 \pm 0.16 \%$.

\section{CONCLUSION}

Bacillus sp. SNRUSA4 was discovered in this study as a novel PLA-food-packagingdegrading bacteria that could degrade both PLA and PLA-food-packaging. The optimal conditions from RSM based on BBD were $Y E$ concentration of $2.56 \%, \mathrm{pH} 7.02$, incubation $T$ of $31.68^{\circ} \mathrm{C}$ and $A S$ of $205.28 \mathrm{rpm}$. Under these conditions, the OD was found at 1.955 , which was 1.752 more than that before optimisation (0.203). Furthermore, the degradation 
of PLA-food-packaging under optimal conditions was also higher than before optimisation due to the increasing weight loss of PLA-food-packaging. The degradation of PLA-foodpackaging under optimal conditions was almost twelve times greater than before the optimisation. Based on the current study, Bacillus sp. SNRUSA4 is a promising strain for the degradation of PLA-food-packaging. The degradation of PLA-food-packaging by Bacillus sp. SNRUSA4 in its natural state should be further studied.

\section{ACKNOWLEDGEMENTS}

This research was supported by the instrument used for study from Sakon Nakhon Rajabhat University, Thailand.

\section{REFERENCES}

Apinya, T., Sombatsompop, N., \& Prapagdee, B. (2015). Selection of a Pseudonocardia sp. RM423 that accelerates the biodegradation of poly (lactic) acid in submerged cultures and in soil microcosms. International Biodeterioration and Biodegradation, 99, 23-30. doi: 10.1016/j.ibiod.201 5.01.001

Biniarz, P., Coutte, F., Gancel, F., \& Łukaszewicz, M. (2018). High-throughput optimization of medium components and culture conditions for the efficient production of a lipopeptide pseudofactin by Pseudomonas fluorescens BD5. Microbial Cell Factories, 17(1), 1-18. doi: 10.1186/s12934-018-0968-x

Boonmee, C., Kositanont, C., \& Leejarkpai, T. (2016). Degradation of poly (lactic acid) under simulated landfill conditions. Environment and Natural Resources Journal, 14(2), 1-9. doi: 10.14456/ennrj.2016.8

Bratcher, D. F. (2018). Bacillus species (Anthrax). In S. S. Long, C. G. Prober \& M. Fischer (Eds.), Principles and Practice of Pediatric Infectious Diseases (pp. 770-773). Philadelphia, PA: Elsevier. doi: 10.1016/ b978-0-323-401 81-4.00129-8

Brosius, J., Dull, T. J., Sleeter, D. D., \& Noller, H. F. (1981). Gene organization and primary structure of a ribosomal RNA operon from Escherichia coli. Journal of Molecular Biology, 148(2), 107-127. doi: https:// doi.org/10.1016/0022-2836(81)90508-8

Bubpachat, T., Sombatsompop, N., \& Prapagdee, B. (2018). Isolation and role of polylactic acid-degrading bacteria on degrading enzymes productions and PLA biodegradability at mesophilic conditions. Polymer Degradation and Stability, 152, 75-85. doi: 10.1016/j.poly mdegradstab.2018.03.023

Butbunchu, N., \& Pathom-Aree, W. (2019). Actinobacteria as promising candidate for polylactic acid type bioplastic degradation. Frontiers in Microbiology, 10, 1-10. doi: 10.3389/fmicb.2019.02834

Chaisu, K., Charles, A. L., Guu, Y. K., \& Chiu, C. H. (2012). Optimization of polylactic acid (PLA) plastic degradation by Aneurinibacillus migulanus using response surface methodology. In International Conference on Biological and Life Sciences (pp. 22-27). Singapore: International Association of Computer Science and Information Technology (IACSIT) Press.

Chen, X. C., Bai, J. X., Cao, J. M., Li, Z. J., Xiong, J., Zhang, L., ... \& Ying, H. J. (2009). Medium optimization for the production of cyclic adenosine 3', 5'-monophosphate by Microbacterium sp. no. 205 using 
response surface methodology. Bioresource Technology, 100(2), 919-924. doi: https://doi.org/10.1016/j. biortech.2008.07.062

Decorosi, F., Exana, M. L., Pini, F., Adessi, A., Messini, A., Luciana Giovannetti, L., \& Viti, C. (2019). The degradative capabilities of new Amycolatopsis isolates on polylactic acid. Microorganisms, 7(590), 1-18. doi: 10.3390/microorganisms 7120590

Elsawy, M. A., Kim, K., Park, J., \& Deep, A. (2017). Hydrolytic degradation of polylactic acid (PLA) and its composites. Renewable and Sustainable Energy Reviews, 79, 1346-1352. doi: https://doi.org/10.1016/j. rser.2017.05.143

Farah, S., Anderson, D. G., \& Langer, R. (2016). Physical and mechanical properties of PLA, and their functions in widespread applications - A comprehensive review. Advanced Drug Delivery Reviews, 107, 367-392. doi: 10.1016/j.addr.2016.06.012

Felsenstein, J. (1985). Confidence limits on phylogenies: An approach using the bootstrap. Evolution, 39, 783-791. doi: 10.1111/j.1558-5646.1985. t b00420.x

Hall, T. A. (1999). BioEdit: A user-friendly biological sequence alignment editor and analysis program for Windows 95/98/NT. Nucleic Acids Symposium Series, 41, 95-98.

Hassaan, M. S., Soltan, M. A., \& Ghonemy, M. M. R. (2014). Effect of synbiotics between Bacillus licheniformis and yeast extract on growth, hematological and biochemical indices of the Nile tilapia (Oreochromis niloticus). The Egyptian Journal of Aquatic Research, 40(2), 199-208. doi: 10.1016/j.ejar.2014.04.001

Janorkar, A. V., Metters, A. T., \& Hirt, D. E. (2007). Degradation of poly(L-lactide) films under ultravioletinduced photografting and sterilization conditions. Journal of Applied Polymer Science, 106(2), 10421047. doi: https://doi.org/10.1002/app.24692

Jarerat, A., \& Tokiwa, Y. (2003). Poly (L-lactide) degradation by Saccharothrix waywayandensis. Biotechnology Letters, 25(5), 401-404. doi: 10.1023/a:1022450431193

Jarerat, A., Tokiwa, Y., \& Tanaka, H. (2003). Poly (L-lactide) degradation by Kibdelosporangium aridum. Biotechnology Letters, 25(23), 2035-2038. doi: 10.1023/b:bile.0000004398.38799.29

Jeon, J. H., \& Kim, N. M. (2013). Biodegradation of poly(L-lactide) (PLA) exposed to UV irradiation by a mesophilic bacterium. International Biodeterioration and Biodegradation, 85, 289-293. doi: 10.1016/ jib iod.2013.08.013

Kalil, M. S., Alshiyab, H. S., \& Yusoff, W. M. W. (2008). Effect of nitrogen source and carbon to nitrogen ratio on hydrogen production using C. acetobutylicum. American Journal of Biochemistry and Biotechnology, 4(4), 393-401. doi: 10.3844/ajbbsp.2008.393.401

Karamanlioglu, M., Houlden, A., \& Robson, G. D. (2014). Isolation and characterisation of fungal communities associated with degradation and growth on the surface of poly(lactic) acid (PLA) in soil and compost. International Biodeterioration and Biodegradation, 95, 301-310. doi: 10.1 016/j.ibiod.2014.09.006

Khatoon, H., \& Rai, J. P. N. (2020). Optimization studies on biodegradation of atrazine by Bacillus badius ABP6 strain using response surface methodology. Biotechnology Reports, 26, 1-10. doi: 10.1016/j. btre.20 20.e00459 
Kim, M. N., \& Park, S. T. (2010). Degradation of poly (L-lactide) by a mesophilic bacterium. Journal of Applied Polymer Science, 117, 67-74. doi: 10.1002/app.31950

Kim, M. Y., Kim, C., Moon, J., Heo, J., Jung, S. P., \& Kim, J. R. (2017). Polymer film-based screening and isolation of polylactic Acid (PLA)- degrading microorganisms. Journal of Microbiology and Biotechnology, 27(2), 342-349. doi: https://doi.org/ 10.4014/jmb.1610.10 015

Kim, O. Y., Mahboob, S., Viayaraghavan, P., Biji, D., Ghanim, A. A. K., Misned, A. F., .. \& Kim, H. J. (2020). Growth promoting activity of Penaeus indicus by secondary metabolite producing probiotic bacterium Bacillus subtilis isolated from the fish gut. Journal of King Saud University-Science, 32(2), 1641-1646. doi: 10.1016/j.jksus.201 9.12 .023

Konkit, M., Jarerat, A., Khanongnuch, C., Lumyong, S., \& Pathom-aree, W. (2012). Poly(lactide) degradation by Pseudonocardia alni AS4.1531(T). Chiang Mai Journal of Science, 39(1), 128-132.

Lee, J. S., Park, H. E., Han, H. Y., Kim, O. Y., \& Park, W. S. (2013). Isolation of a marine bacterium capable of biodegrading poly (butylene succinate). Journal of Fisheries and AquaticSciences, 16(1), 41-44. doi: 10.5657/FAS.2013.0041

Liang, T. W., Jen, S. N., Nguyen, A. D., \& Wang, S. L. (2016). Application of chitinous materials in production and purification of a poly (L-lactic acid) depolymerase from Pseudomonas tamsuii TKU015. Polymers, 8(98), 1-11. doi: 10.3390/polym8030098

Lipsa, R., Tudorachi, N., Darie-Nita, R. N., Oprică, L., Vasile, C., \& Chiriac, A. (2016). Biodegradation of poly (lactic acid) and some of its based systems with Trichoderma viride. International Journal of Biological Macromolecules, 88, 515-526. doi: 10.1016/j.ijbiomac.2016.04.017

Logan, N. A., \& Vos, P. D. (2015). Bacillus. In W. B. Whitman (Ed.), Bergey's manual of systematics of archaea and bacteria (pp. 1-163). Hoboken, NJ: John Wiley \& Sons, Inc. doi: 10.1002/9781118960608.gbm 00530

Mirabal, A. S., Scholz, L., \& Carus, M. (2013). Bio-based polymers in the world capacities, production and applications: Status quo and trends towards 2020. Retrieved August 19, 2020, from http://bio-based.eu/ market_study/media/files/13-06 21MSBiopolymersExcerpt .pdf

Mohammed, S., Behera, H. T., Dekebo, A., \& Ray, L. (2019). Optimization of the culture conditions for production of polyhydroxyalkanoate and its characterization from a new Bacillus cereus sp. BNPI-92 strain, isolated from plastic waste dumping yard. International Journal of Biological Macromolecules, 156, 1064-1080. doi: 10.1016/j.ijbiomac .2019.11.138

Mohanrasu, K., Rao, R. G. R., Dinesh, G. H., Zhang, K., Prakash, G. S., Song, D. P., .. \& Arun, A. (2020). Optimization of media components and culture conditions for polyhydroxyalkanoates production by Bacillus megaterium. Fuel, 271, 1-9. doi: 10.1016/j.fuel.2020.117522

Muhonja, C. N., Makonde, H., Magoma, G., \& Imbuga, M. (2018). Biodegradability of polyethylene by bacteria and fungi from Dandora dumpsite Nairobi-Kenya. PloS One, 13(7), 1-17. doi: 10.1371/jour nal. pone.0198446

Muller, J., González-Martínez, C., \& Chiralt, A. (2017). Combination of poly (lactic) acid and starch for biodegradable food packaging. Materials, 10(952), 1-22. doi: 10.3390/ma10080952 
Naskar, A., Majumder, R., \& Goswami, M. (2020). Bioaccumulation of Ni(II) on growing cells of Bacillus sp. response surface modeling and mechanistic insight. Environmental Technology and Innovation, 20, 1-39. doi: 10.1016/j.eti.2020.101057

Ojha, S. K., Singh, P. K., Mishra, S., Pattnaik, R., Dixit, S., \& Verma, S. K. (2020). Response surface methodology based optimization and scale-up production of amylase from a novel bacterial strain, Bacillus aryabhattai KIIT BE-1. Biotechnology Reports, 27, 1-9. doi: 10.1016/ j.btre.2020.e00506

Penkhrue, W., Khanongnuch, C., Masaki, K., Pathom-aree, W., Punyodom, W., \& Lumyong, S. (2015). Isolation and screening of biopolymer-degrading microorganisms from northern Thailand. World Journal of Microbiology and Biotechnology, 3, 1431-1442. doi: 10.1007/s1127 4-015-1895-1

Phukon, P., Saikia, J. P., \& Konwar, B. K. (2012). Bio-plastic (P-3HB-co-3HV) from Bacillus circulans (MTCC 8167) and its biodegradation. Colloids and Surfaces B: Biointerfaces, 92, 30-34. doi: 10.1016/j. co lsurfb.2011.11.011

Qi, F. F., Huang, M. H., Zheng, Y., \& Xu, Q. (2015). Optimization of an A2/O process for tetracycline removal via response surface methodology coupled with a Box-Behnken design. Journal of Environmental Science and Health, 50(7), 735-743. doi: 10.1080/109 34529.2015.1011981

Qi, X., Ren, Y., \& Wang, X. (2017). New advances in the biodegradation of poly (lactic) acid. International Biodeterioration and Biodegradation, 117, 215-223. doi: 10.1016/j.ibiod.2017.01.010

Saitou, N., \& Nei, M. (1987). The neighbor-joining method: A new method for reconstructing phylogenetic trees. Molecular Biology and Evolution, 4, 406-425. doi: 10.1093/oxfordjournals.molbev.a040454

Szumigaj, J., Zakowska, Z., Klimek, L., Rosicka-Kaczmarek, J., \& Bartkowiak, A. (2008). Assessment of polylactide foil degradation as a result of filamentous fungi activity. The Polish Journal of Environmental Studies, 17(3), 335-341.

Tamura, K., Stecher, G., Peterson, D., Filipski, A., \& Kumar, S. (2013). MEGA6: Molecular evolutionary genetics analysis version 6.0. Molecular Biology and Evolution, 30(12), 2725-2729. doi: 10.1093/m olbev/mst197

Tawakkal, I. S. M. A., Cran, M. J., Miltz, J., \& Bigger, S. W. (2014). A Review of poly (lactic acid)-based materials for antimicrobial packaging. Journal of Food Science, 79(8), 1477-1490. doi: 10.1111/1 7503841.12534

Thompson, J. (1997). The clustal_x windows interface: Flexible strategies for multiple sequence alignment aided by quality analysis tools. Nucleic Acids Research, 25(24), 4876-4882. doi: 10.1093/nar /25.24.4876

Tian, Y., Fan, Y., Liu, J., Zhao, X., \& Chen, W. (2016). Effect of nitrogen, carbon sources and agitation speed on acetoin production of Bacillus subtilis SF4-3. Electronic Journal of Biotechnology, 19, 41-49. doi: 1 0.1016/j.ejbt.2015.11.005

Unrean, P., Nguyen, N. H. A., Visessanguan, W., \& Kitsubun, P. (2012). Improvement of nattokinase production by Bacillus subtilis using an optimal feed strategy in fed-batch fermentation. KKU Research Journal, 17(5), 769-777.

Vey, E., Miller, A. F., Claybourn, M., \& Saiani, A. (2007). In vitro degradation of poly (lactic-co2-glycolic) acid random copolymers. Macromolecular Symposia, 251(1), 81-87. doi: 10.1002/masy.20075 0511 
Yottakot, S., \& Leelavatcharamas, V. (2019). Isolation and optimisation of polylactic acid (PLA)-packaging degrading actinomycete for PLA-packaging degradation. Pertanika Journal of Tropical Agricultural Science, 42(3), 1111-1130.

Yun, T. Y., Feng, R. J., Zhou, D. B., Pan, Y. Y., Chen, Y. F., Wang, F., ... \& Xie, J. H. (2018). Optimization of fermentation conditions through response surface methodology for enhanced antibacterial metabolite production by Streptomyces sp. 1-14 from cassava rhizosphere. PloS One, 13(11), 1-21. doi: https://doi. org/10.1371/journal.pone.0206497

Zhong, Y., Godwin, P., Jin, Y., \& Xiao, H. (2020). Biodegradable polymers and green-based antimicrobial packaging materials: A mini-review. Advanced Industrial and Engineering Polymer Research, 3, 27-35. doi: 10.1016/j.aiepr.2019.11.002

Zhou, Y., Sun, Y. B., He, H. W., Feng, J. T., Zhang, X., \& Han, L. R. (2017). Optimization of medium compositions to improve a novel glycoprotein production by Streptomyces kanasenisi ZX01. AMB Express, 7(1), 1-9. doi: 10.1186/s13568-016-0316-7 
